\title{
A shock tube and modeling study on the autoignition properties of
}

\section{ammonia at intermediate temperatures}

B. Shu ${ }^{1 *}$, S. K. Vallabhuni ${ }^{1}$, X. $\mathrm{He}^{1}$, G. Issayev ${ }^{2}$, K. Moshammer ${ }^{1}$, A. Farooq ${ }^{2}$, R. X. Fernandes ${ }^{1}$

${ }^{1}$ Physikalisch-Technische Bundesanstalt (PTB), Department of Thermophysical Quantities, Braunschweig, Germany

${ }^{2}$ King Abdullah University of Science and Technology (KAUST), Clean Combustion Research Center, Physical Sciences and Engineering Division, Thuwal 23955, Saudi Arabia

*Corresponding Author:

Bo Shu

Physikalisch-Technische Bundesanstalt (PTB)

Department of Thermophysical Quantities, Reaction Kinetics

38116 Braunschweig

GERMANY

Phone: $+49(0) 531592-3276$

Fax: +49 (0) $531592-3305$

Email: bo.shu@ptb.de

Colloquium: Gas-phase reaction kinetics

Word equivalent length of 


\title{
A shock tube and modeling study on the autoignition properties of ammonia at intermediate temperatures
}

\author{
B. Shu ${ }^{1 *}$, S. K. Vallabhuni ${ }^{1}$, X. He ${ }^{1}$, G. Issayev ${ }^{2}$, K. Moshammer ${ }^{1}$, A. Farooq ${ }^{2}$, R. X. Fernandes ${ }^{1}$ \\ ${ }^{1}$ Physikalisch-Technische Bundesanstalt (PTB), Department of Thermophysical Quantities, Braunschweig, Germany \\ ${ }^{2}$ King Abdullah University of Science and Technology (KAUST), Clean Combustion Research Center, Physical \\ Sciences and Engineering Division, Thuwal 23955, Saudi Arabia
}

\begin{abstract}
Ammonia $\left(\mathrm{NH}_{3}\right)$, has been considered as a promising alternative energy carrier for automobile engines and gas turbines due to its production from renewable sources using concepts such as power-to-gas. Knowledge of the combustion characteristics of $\mathrm{NH}_{3}$ /air and the formation of pollutants, especially $\mathrm{NO}_{x}$ and unburned $\mathrm{NH}_{3}$, at intermediate temperatures is crucially important to investigate. Detailed understanding of ammonia reaction mechanism is still lacking. The present study reports ignition delay times of $\mathrm{NH}_{3} /$ air mixtures over a temperature range of $1100-1600 \mathrm{~K}$, pressures of 20 and 40 bar, and equivalence ratios of $0.5,1.0$, and 2.0. The experimental results are compared to the literature mechanism of Mathieu and Petersen (2015), and reasonable agreement is observed. Detailed modeling for ammonia emissions is performed, and the $\mathrm{NH}_{3}$ /air combustion is found to be potentially free from $\mathrm{NO}_{\mathrm{x}}$ and unburned $\mathrm{NH}_{3}$ at fuel-rich conditions.
\end{abstract}

Keywords: Ammonia, Shock tubes, Auto-ignition delays, Chemical kinetics, Modeling 


\section{Introduction}

Ammonia $\left(\mathrm{NH}_{3}\right)$ has been identified as a promising alternative fuel for future transportation and energy systems. Considering the rigorous regulations of greenhouse gas emissions and increasing demand of renewable energy carriers, ammonia appears to be one of the most viable solutions to our energy crisis. Ammonia does not produce any soot or $\mathrm{CO}_{2}$ during its chemical conversion process due to its carbon free character and it can be produced from renewable sources using concepts such as power-to-gas [1]. $\mathrm{NH}_{3}$ has a higher hydrogen density and is thus a promising green energy storage carrier. It can be potentially burned in an environmentally friendly way producing only nitrogen and water. However, the emission of pollutants such as $\mathrm{NO}_{\mathrm{x}}$ and unburned $\mathrm{NH}_{3}$ is still unclear and detailed investigations are required.

Experimental investigations for $\mathrm{NH}_{3}$ oxidation have been performed in various reactors [2-11], and several detailed combustion mechanisms containing ammonia sub-mechanisms were developed during the last decades [12-19]. Most of the reported experimental measurements focused on conditions at elevated temperature $(>1500 \mathrm{~K})$ and low-pressure regimes $(<10$ bar). Recently, Mathieu and coworkers [20] studied the ignition delay time of $\mathrm{NH}_{3}$ at high temperatures (1560-2455 K) covering pressures of 11 and 30 bar, and introduced an improved mechanism to model their experimental results. Nakamura et al. [21] reported a study of $\mathrm{NH}_{3}$ /air weak flame in a micro-flow reactor under a maximum wall temperature of $1400 \mathrm{~K}$ at atmospheric pressure, and proposed a mechanism which adequately predicted the species profiles of $\mathrm{NH}_{3}, \mathrm{O}_{2}$, and $\mathrm{H}_{2} \mathrm{O}$. However, experimental data for the auto-ignition characteristics of $\mathrm{NH}_{3} /$ air at the intermediate temperature regime (1000-1500 K) and pressures higher than 10 bar is still lacking, which would be needed for model validation.

The objective of this study is, therefore, to investigate the ignition delay times of $\mathrm{NH}_{3}$ /air mixtures, validate the literature mechanisms, and numerically analyze the emissions under the studied conditions. A contrasting difference of our work compared to previous ignition delay studies is the use of ammonia/air mixtures, which are more relevant to practical applications. Experiments were 
performed in a shock tube behind reflected shock waves, for pressures near 20 and 40 bar, temperatures of $1100-1600 \mathrm{~K}$, and equivalence ratios of $0.5,1.0$, and 2.0 . The obtained results were compared to a chemical kinetic mechanism from Mathieu and Petersen [20], and sensitivity analysis was performed at crucial operating conditions to evaluate the role of the reactions and their associated uncertainties are discussed. Furthermore, these results serve as basis for screening $\mathrm{NH}_{3}$ for its potential future use as "pollutant free" fuel under certain operating conditions as well as to set new fuel standards for advanced propulsion applications.

\section{Experimental Details}

Ignition delay experiments were performed at the King Abdullah University of Science and Technology (KAUST) in a high-pressure shock tube (HPST). The details of this apparatus can be found in Ref. [22]. Briefly, the HPST was made of stainless steel with an inner diameter of $10 \mathrm{~cm}$. The driven section is $6.6 \mathrm{~m}$ long, and the driver section has a modular design to vary its length from $2.2 \mathrm{~m}$ to a maximum of $6.6 \mathrm{~m}$. The mid-section of the shock tube houses two pre-scored aluminum diaphragms in a double diaphragm configuration which allows better control of the post reflected shock conditions compared to a single diaphragm configuration. The inner surface of the shock tube is electropolished to reduce the effects of boundary layers.

Incident shock wave was monitored with five equally separated PCB $113 \mathrm{~B} 26$ pressure transducers placed axially along the last $3.7 \mathrm{~m}$ from the end wall of the driven section. Thermodynamic states behind the reflected shock wave, i.e., $p_{5}$ and $T_{5}$, were calculated using a one-dimensional shock model. Uncertainties in the measurement of pressure and temperature are less than $1 \%$.

A molar ratio of 3.76:1 of $\mathrm{N}_{2}: \mathrm{O}_{2}$ was used to prepare $\mathrm{NH}_{3}$ /air mixtures in a magnetically-stirred mixing tank. The shock tube and mixing tank were heated to $90^{\circ} \mathrm{C}$ through heating jackets and isolation bands to avoid fuel condensation during experiments. All mixtures were manometrically prepared and stirred overnight prior to use. Ammonia has a strong tendency to adsorb to the walls of mixing vessel and 
shock tube. This was overcome by using the 'passivation' technique, whereby the walls were allowed to saturate, i.e., to reach adsorption-desorption equilibrium, with ammonia before filling in the final mixture.

Ammonia/air mixtures were investigated in a temperature range of $1100-1600 \mathrm{~K}$, at pressures of 20 and 40 bar, equivalence ratios of $0.5,1.0$, and 2.0. To perform low temperature experiments $(\mathrm{T}<1200$ $\mathrm{K}$ ), driver gas was tailored with $\mathrm{He} / \mathrm{N}_{2}$ blends to obtain longer test times using the procedure of Amadio et al. [23].

Ignition delay times were determined using the signals from pressure diagnostics and $\mathrm{OH}^{*}$ chemiluminescence detected at the end wall of the shock tube. Figure 1 displays a typical pressure profile where the ignition delay time is defined as the time interval between the passage of the reflected shock wave (time zero) and the intersection of line drawn along the steepest rate-of-change of pressure rise and a horizontal line which defines the $p_{5}$. Overall, the total uncertainty of the reported ignition delay times in this study is estimated to be less than $20 \%$. Since ammonia is a relatively unreactive fuel, both pressure and $\mathrm{OH}^{*}$ emission signals exhibited a slow gradual rise before the main ignition event.

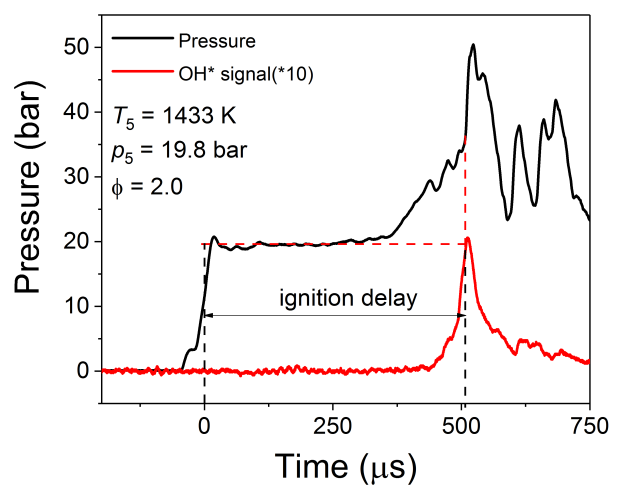

Figure 1: Typical pressure profile (black solid line) and corresponding $\mathrm{OH}^{*}$ signal (solid red line) as well as the determination of the ignition delay time (dashed line). 


\section{Kinetic Modeling}

The reaction mechanism of Mathieu and Petersen [20] was employed for simulations and compared to the measured shock tube data. The mechanism contains 35 species and 159 reactions, and was validated by Mathieu and co-workers against ignition delay times measured behind reflected shock waves at high temperatures (1560-2455 K), from low to high pressures $(1.4,11$, and 30 bar) and three equivalence ratios $(0.5,1.0$, and 2.0$)$ with highly diluted $\mathrm{NH}_{3} / \mathrm{O}_{2}$ mixtures in Ar. The original model was based on a mechanism proposed by Dagaut et al. [17] and extended by Mathieu and co-workers using $\mathrm{H}_{2} / \mathrm{O}_{2} / \mathrm{CO}, \mathrm{NO}_{\mathrm{x}}$, and $\mathrm{NNH}$ sub-mechanisms from literature [19,24-27]. However, the mechanism could not be validated at intermediate temperatures and high pressures due to the lack of data which are the conditions investigated in this work.

The simulations were performed using an in-house Cantera code based on a homogeneous reactor at constant volume. To accurately reproduce the reaction environment in the shock tube, gas dynamic effects were considered for kinetic simulations following the methodology described in a previous study [28]. The simulated ignition delay times were determined at the intersection of lines drawn along the steepest rate-of-change of $\mathrm{OH}^{*}$ and the horizontal line which defines the zero-concentration level.

\section{Results and Discussions}

Measured ignition delays are plotted as a function of temperature in Figs. 2 and 3; detailed experimental data can be found in the Supplementary Material. Figure 2 shows the effects of the equivalence ratio on the ignition delay time at pressures around 20 and 40 bar. As can be seen, at both pressures, the ignition delay times obtained at stoichiometric and fuel-rich conditions are very similar, while the ignition delay times at fuel-lean condition $(\phi=0.5)$ seem to be slightly longer than for the other conditions. This result is opposite to the findings of Mathieu and Petersen [20] in their measurements at high pressures (11 and 30 bar), where the ignition delay times at $\phi=0.5$ were shorter than those at $\phi=1.0$ and 2.0. Note that the investigated temperature region $(1100-1600 \mathrm{~K})$ in this study 
is lower than that from Mathieu and Petersen $(1560-2455 \mathrm{~K})$ and the auto-ignition behavior of $\mathrm{NH}_{3}$ can be changed in the different temperature regimes.
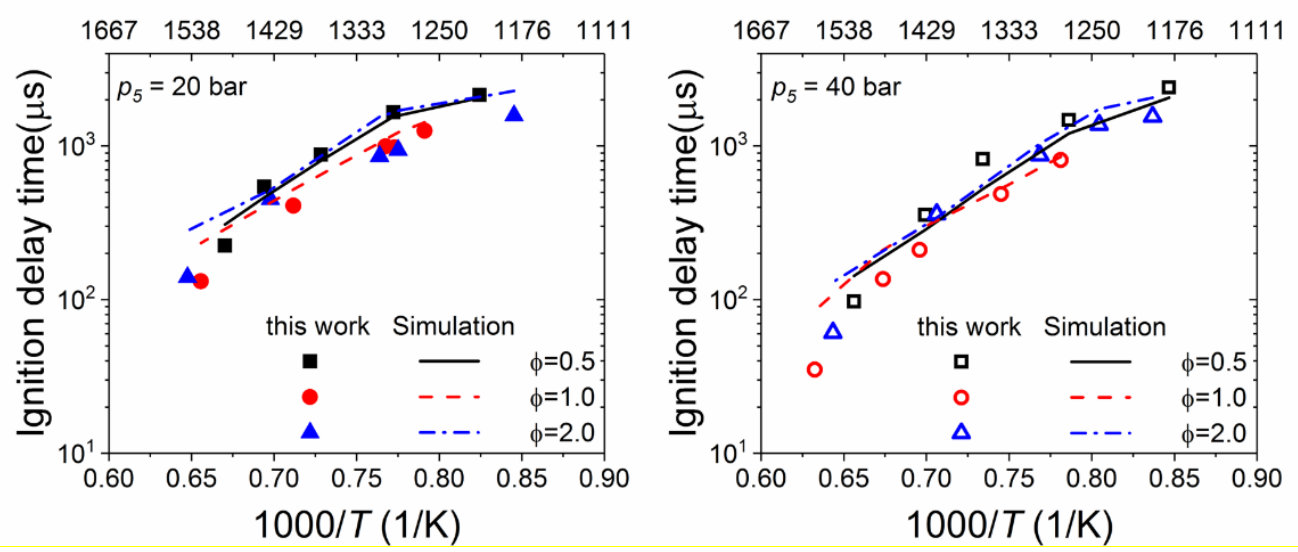

Figure 2: Effects of equivalence ratio on the ignition delay time of $\mathrm{NH}_{3} /$ air mixtures at 20 and 40 bar. Simulation are based on the mechanism of Mathieu and Petersen [20].

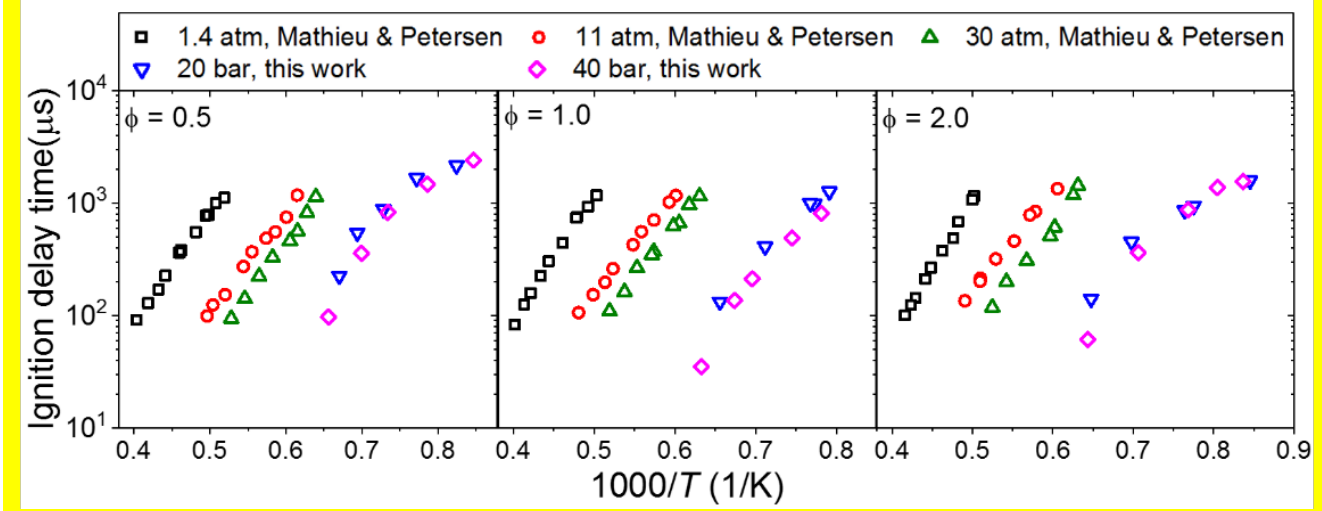

Figure 3: Comparison of experimental dataset from this study and Mathieu and Petersen [20]

Figure 3 presents variation of ignition delay times with pressure at various equivalence ratios. Also included in this figure are measured data from Mathieu and Petersen [20] at 1.4, 11, and 30 atm using $\mathrm{NH}_{3} / \mathrm{O}_{2} /$ Ar mixtures. As expected, ignition delay times decrease with increasing pressure. However, the differences between the two measured pressures in this work (20 and 40 bar) are smaller in the low-temperature region. At fuel-rich condition $(\phi=2.0)$, ignition delay times at both pressures are very close to each other near $1170 \mathrm{~K}$. A similar pressure effect can be found in the data set from Mathieu and Petersen [20] although their data are mostly in a higher temperature regime. 
It is noted that the ignition delay times obtained in this study at the highest temperature near $1600 \mathrm{~K}$ and at all equivalence ratios are much shorter compared to the data obtained by Mathieu and Petersen [20]. Despite the different pressure regimes in both studies, this significant difference is probably attributed to the different mixture dilutions used for the measurements. Mathieu and Petersen used highly diluted $\mathrm{NH}_{3} / \mathrm{O}_{2}$ mixtures in $\mathrm{Ar}(99 \%$ and $98 \%)$ whereas non-diluted mixtures of $\mathrm{NH}_{3} /$ air were used in our study. A strong effect of the fuel concentration on the ignition delay time was already observed by Mathieu and co-workers, where the $98 \%$ dilution case showed shorter ignition delay time compared to $99 \%$ dilution case by almost a factor of 2 . Moreover, presence of $\mathrm{N}_{2}$ instead of $\mathrm{Ar}$ as the diluent gas may also lead to slightly different ignition behavior due to their relatively different heat capacities.

To rationalize the comparison between different measurements, the mechanism of Mathieu and Petersen [20], which was developed to predict their ignition delay times, is used here to compare with the data obtained in our study. Comparison between the simulated and measured ignition delay times at all conditions can be found in Fig. 1. At fuel-lean condition $(\phi=0.5)$, ignition delay times predicted by the mechanism show very good agreement with our measurements. The simulated and measured ignition delay times compare very well for both pressures and only slightly under-predicted for the measured temperature regime. For the highest temperature case at $1600 \mathrm{~K}$ and $40 \mathrm{bar}$, the model overpredicted the ignition delay time by factor of 1.5 .

Good agreement was also found between the simulations and measurements for stoichiometric and fuel-rich mixtures. Overall, the mechanism over-predicts the ignition delay times for both equivalence ratios. At stoichiometric condition $(\phi=1.0)$, the simulated and measured ignition delay times are very close to each other at $T<1300 \mathrm{~K}$. However, the deviation becomes larger with increase of temperature; the simulated ignition delay time is longer than the experimental results by a factor of 2 near $1600 \mathrm{~K}$. The discrepancy between simulation and measurement becomes larger at fuel-rich conditions $(\phi=2.0)$. Generally, the measurement shows shorter ignition delay time than the simulation by a factor of 2 . The 
simulations show better agreement for temperatures between 1300 and $1400 \mathrm{~K}$ and are within the experimental uncertainty.

As the mechanism of Mathieu and Petersen [20] predicts fuel-lean data better than stoichiometric and fuel-rich data, and to get insights into the crucial elementary reactions influencing the auto-ignition, sensitivity analysis (SA) was performed for the conditions where significant deviations between the model predictions and the experimental results were observed. Furthermore, we used literature reported mechanisms from Mathieu and Petersen [20], Dagaut et al. [17], Klippenstein et al. [19], and Nakamura et al. [21] to check for any inconsistencies on the chemical reaction pathways and the adopted rate coefficients. Hydroxyl $(\mathrm{OH}) \mathrm{SA}$ was carried out at the time of ignition for $\phi=2.0, T=$ $1183 \mathrm{~K}$, and $p=20$ bar, and the results are presented in Fig. 4 and Fig. S1. Almost all mechanisms indicate similar chemistry of auto-ignition except for Nakamura et al. [21] where the SA shows significant differences in the chemistry influencing auto-ignition (cf. Fig. S1). This is also well reflected in the overall predicted ignition delays shown in Fig 5, where the predictions from the mechanism of Nakamura et al. strongly underestimates the ignition delays for the fuel-rich mixture at 20 bar while the other mechanism show almost identical results. For simplification purpose, we would only discuss here the Mathieu and Petersen mechanism, the predictions of which describe best our experimental results.

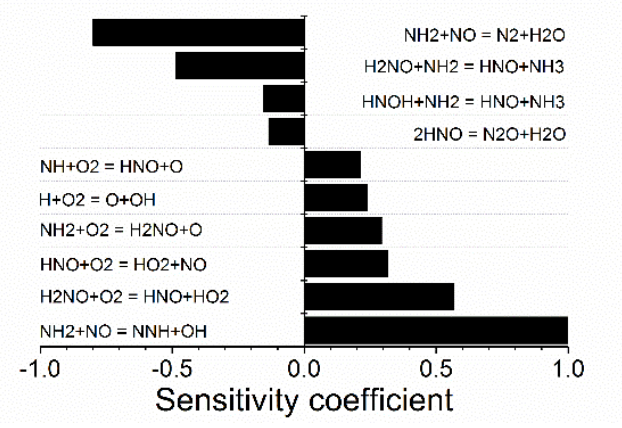

Figure 4: Normalized sensitivity analysis on $\mathrm{OH}$ radical at time of ignition for a $\mathrm{NH}_{3} /$ air mixture at $\phi=2.0, T=1183 \mathrm{~K}$, and $p=20$ bar based on the mechanism of Mathieu and Petersen [20]. 


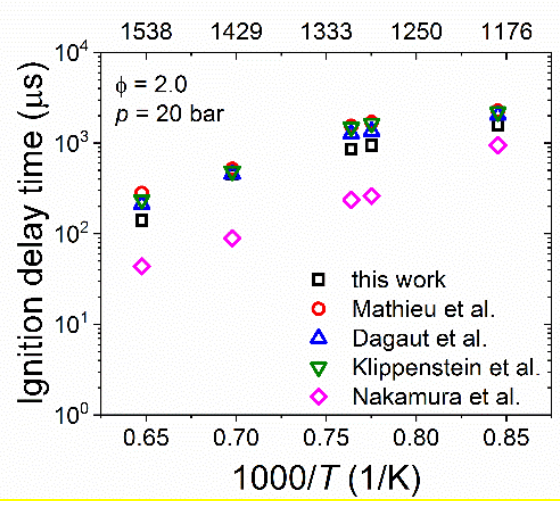

Figure 5: Comparison of experimental results with the model predictions from the literature [17,19-21] for the fuel-rich mixture at 20 bar.

Sensitivity analysis (Fig. 4) show that the most dominant reactions are the competitive bimolecular branching reaction of $\mathrm{NH}_{2}+\mathrm{NO}$ to $\mathrm{N}_{2} \mathrm{H}+\mathrm{OH}$ (ignition enhancing channel) and the reaction to the stable species $\mathrm{N}_{2}+\mathrm{H}_{2} \mathrm{O}$ (hindering ignition). Figure 6 shows the reaction pathway analysis for $\mathrm{NH}_{3} /$ air at time of ignition at $1200 \mathrm{~K}$ and 20 bar. The amino radical $\left(\mathrm{NH}_{2}\right)$ is found to be the central species in the radical pool and it is responsible for chain propagation and branching. It is primarily formed by the initiation reactions of the fuel $\left(\mathrm{NH}_{3}\right)$ through reactions with small radicals such as $\mathrm{O}, \mathrm{OH}$ and $\mathrm{H}$ or the subsequent reaction of $\mathrm{NH}_{3}$ with the highly reactive species $\mathrm{HNO}$, which is present in the reaction system through oxidation of $\mathrm{NH}$ or $\mathrm{H}_{2} \mathrm{NO}$. The amino radical can also be recycled back to $\mathrm{NH}_{3}$ via the reaction with $\mathrm{H}_{2} \mathrm{NO}$, the latter being formed by the consequent reaction of $\mathrm{NH}_{2}+\mathrm{O}_{2}$. The reaction of $\mathrm{NH}_{2}+\mathrm{NO}$ is the most significant reaction for auto-ignition of ammonia, and the branching ratio producing $\mathrm{N}_{2} \mathrm{H}+\mathrm{OH}$ and to $\mathrm{N}_{2}+\mathrm{H}_{2} \mathrm{O}$ under wide temperature and pressure conditions is the most crucial parameter either triggering or hindering auto-ignition. The rate coefficients and the branching ratio of the reactions $\mathrm{NH}_{2}+\mathrm{NO}$ were obtained from the studies of Miller and Glarborg [29], these reaction rates were then also replaced with the more recent study from Klippenstein et al. [19] to check for any inconsistencies in model predictions. There were no significant deviations obtained in the simulation results using reaction rates from either of the previous studies. The other sensitive reactions are those producing $\mathrm{HNO}$ via the reactions of $\mathrm{H}_{2} \mathrm{NO}$ with either $\mathrm{O}_{2}$ or $\mathrm{NH}_{2}$ or direct oxidation of $\mathrm{NH}$ 
with $\mathrm{O}_{2}$ and the formation of oxygen atoms. $\mathrm{H}_{2} \mathrm{NO}$ in turn is formed by the bimolecular reaction of $\mathrm{NH}_{2}$ with molecular oxygen. However, the rate constants of reactions involving $\mathrm{HNO}$ and $\mathrm{H}_{2} \mathrm{NO}$ in literature mechanism were indirectly determined; therefore, further investigation on these reactions are essential.

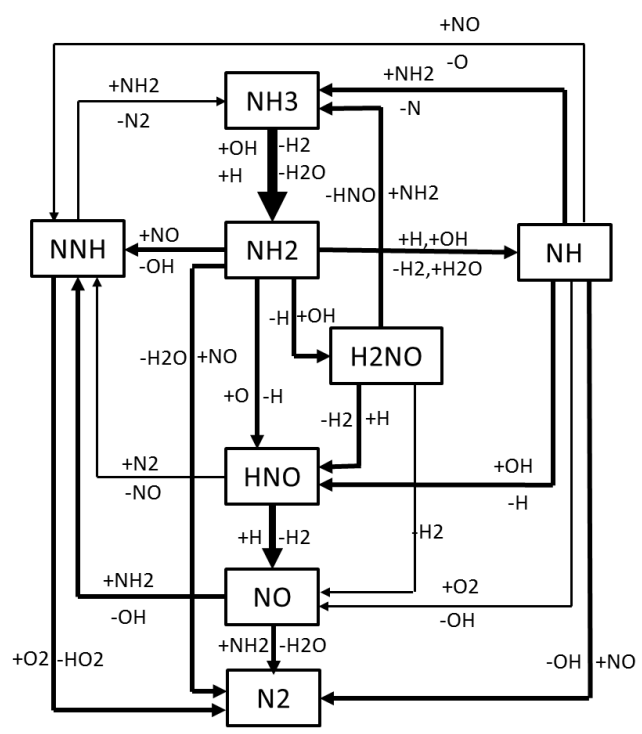

Figure 6: Reaction pathway analysis for the $\mathrm{NH}_{3}$ /air mixture at time of ignition; $T=1200 \mathrm{~K}, p=20$ bar.

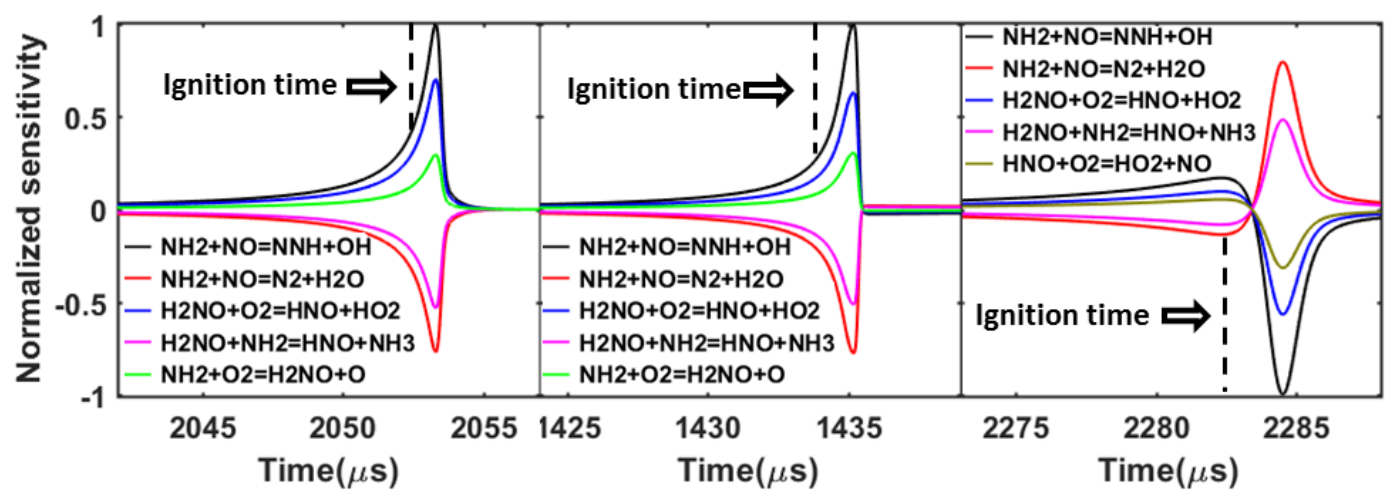

Figure 7: Sensitivity analysis for NO formation and consumption based on the mechanism of Mathieu and Petersen [20] at 20 bar; left: $\phi=0.5, T=1213 \mathrm{~K}$; middle: $\phi=1.0, T=1263 \mathrm{~K}$; right: $\phi=2.0, T=1183 \mathrm{~K}$.

Additionally, we performed a sensitivity analysis for NO formation and its consumption at different equivalence ratios near $1200 \mathrm{~K}$ and 20 bar, which is depicted in Fig. 7. The most sensitive reactions on NO formation prior to the time of ignition for all equivalence ratio are the chain branching reactions of $\mathrm{NH}_{2}+\mathrm{NO}$ to form $\mathrm{NNH}+\mathrm{OH}$ and $\mathrm{H}_{2} \mathrm{NO}+\mathrm{O}_{2}$ to form $\mathrm{HNO}+\mathrm{HO}_{2}$. The time-dependent sensitivity 
analysis indicates that the equilibrium constant for the reaction of $\mathrm{NH}_{2}+\mathrm{NO}$ to $\mathrm{N}_{2} \mathrm{H}+\mathrm{OH}$ is also crucial for NO formation/mitigation. Moreover, as can be seen from the results for high equivalence ratios (Fig. 7 middle and right), at $\phi=1.0$, the reaction of $\mathrm{NH}_{2}+\mathrm{NO}=\mathrm{N}_{2} \mathrm{H}+\mathrm{OH}$ starts to show negative influences on NO formation post-ignition, and this effect becomes much stronger at $\phi=2.0$ indicating a strong consumption of $\mathrm{NO}$ at fuel-rich conditions. The simulated time-dependent NO profile (Fig. 8 left) at different equivalence ratios (1300 K and 20 bar) demonstrate this effect, where the NO emission at $\phi=0.5$ shows a plateau value after the ignition while the NO is consumed immediately after reaching its peak value at $\phi=1.0$ and 2.0. The final concentration of $\phi=2.0$ case is predicted to be only several ppm. This reaction provides the key role for controlling both auto-ignition as well as $\mathrm{NO}_{\mathrm{x}}$ formation and its mitigation. $\mathrm{NH}_{2}$ serves as a key radical species to consume $\mathrm{NO}$ and act as DeNO $\mathrm{x}_{\mathrm{x}}$ agent in the gas phase to yield $\mathrm{N}_{2}$ and $\mathrm{H}_{2} \mathrm{O}-$ a mechanism similar to that in selective catalytic reduction processes.

Furthermore, the product distribution of $\mathrm{NH}_{3}$ and $\mathrm{NO}_{\mathrm{x}}$ was simulated based on the Mathieu and Petersen mechanism [20] to understand the effects of temperature and equivalence ratios on the final emissions because pressure was found to have minor influence on the final concentration of $\mathrm{NO}_{\mathrm{x}}$. As shown in Fig. 8 right, only few residual $\mathrm{NH}_{3}(<50 \mathrm{ppm})$ is found at any simulated conditions. The temperature affects strongly the $\mathrm{NO}_{\mathrm{x}}$ emission. Decreasing the temperature by $100 \mathrm{~K}$, the $\mathrm{NO}_{\mathrm{x}}$ emission can be reduced by about $10 \%$. The equivalence ratio shows remarkable effect on the $\mathrm{NO}_{\mathrm{x}}$ formation, at each condition, the final concentration of $\mathrm{NO}_{\mathrm{x}}$ at $\phi=1.0$ is lower than $\phi=0.5$ with factor of 2 , and the emission of $\mathrm{NO}_{\mathrm{x}}$ at $\phi=2.0$ is only several ppm. It is worth to point out that ammonia oxidation at low temperatures can have negligible $\mathrm{NO}_{\mathrm{x}}$ emissions. In a study by Song et al. [30] on ammonia oxidation in a high-pressure flow reactor at 30 and 100 bar, no $\mathrm{NO}$ and $\mathrm{NO}_{2}$ were detected at $850-875 \mathrm{~K}$ even under fuel-lean conditions. 

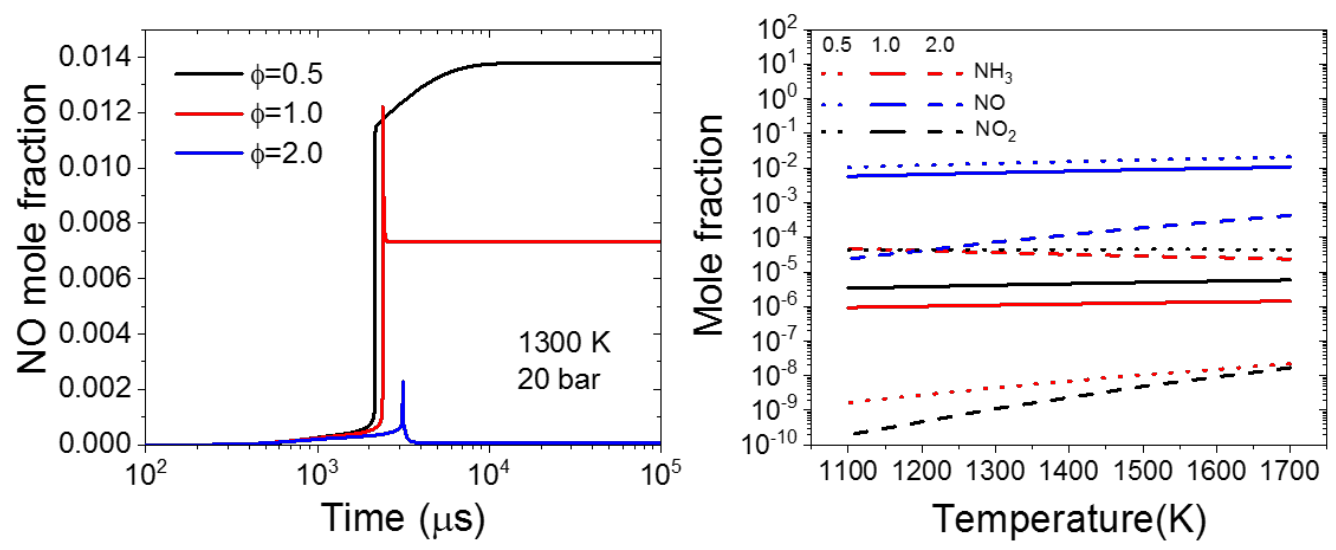

Figure 8: Time-dependent NO profile at $1300 \mathrm{~K}$ and 20 bar at different equivalence ratios (left);

Simulated products distribution as function of the temperature at 20 bar (right). Model: Mathieu and Petersen [20].

\section{Conclusions}

This study reports ignition delay measurements for $\mathrm{NH}_{3}$ in air for three different equivalent ratios $(0.5$, 1.0 , and 2.0$)$ in the intermediate temperature regime $(1100-1600 \mathrm{~K})$ at relatively high pressures $(20$ and 40 bar). These are the first measurements extending the conditions of previous experiments from Mathieu and Petersen [20]. Our data are suggested to be useful for future model refinement and validation. Our experiments as well as the implemented model indicate that under relatively lowtemperature conditions, $\mathrm{NO}_{\mathrm{x}}$ formation can be controlled by selective reduction in the gas phase through its self-reaction with $\mathrm{NH}_{2}$ to form $\mathrm{N}_{2}$ and $\mathrm{H}_{2} \mathrm{O}$. This reaction is equally important in the autoignition of $\mathrm{NH}_{3}$ due to its branching path to form $\mathrm{N}_{2} \mathrm{H}$ and $\mathrm{OH}$. Moreover, high equivalence ratios show a promotion of the consumption of $\mathrm{NO}_{x}$. Initial review of $\mathrm{NH}_{3}$ combustion at low temperatures indicates that $\mathrm{NH}_{3}$ could potentially be a future carbon-free and $\mathrm{NO}_{\mathrm{x}}$ free fuel under specific operating conditions.

\section{Acknowledgements}

All ignition delay experiments were carried out at King Abdullah University of Science and Technology (KAUST). The funding for this work was provided by the Office of Sponsored Research 
at KAUST. Fruitful discussions with Dr. Arnas Lucassen (PTB) and Dr. Olivier Mathieu (Texas A\&M) are gratefully acknowledged. 


\section{References}

[1] J.R. Jennings, Catalytic ammonia synthesis, fundamentals and practice, Plenum Press, New York, United States, 1991.

[2] L. Cohen, Fuel. 34 (1955) 123-127.

[3] N. Fujii, H. Miyama, M. Koshi, T. Asaba, Symp. Combust. 18 (1981) 873-883.

[4] T. Takeyama, H. Miyama, Bull. Chem. Soc. Jpn. 39 (1966) 2609-2612.

[5] T. Takeyama, H. Miyama, Symp. Combust. 11 (1967) 845-852.

[6] H. Miyama, R. Endoh, Combust. Flame 11 (1967) 359-360.

[7] L.J. DRUMMOND, Combust. Sci. Technol. 5 (1972) 175-182.

[8] S. Salimian, R.K. Hanson, C.H. Kruger, Int. J. Chem. Kinet. 16 (1984) 725-739.

[9] A.M. Dean, J.E. Hardy, R.K. Lyon, Symp. Combust. 19 (1982) 97-105.

[10] C.J. Dasch, R.J. Blint, Combust. Sci. Technol. 41 (1984) 223-244.

[11] D.I. Maclean, H.G. Wagner, Symp. Combust. 11 (1967) 871-878.

[12] A.A. KONNOV, J. DE RUYCK, Combust. Sci. Technol. 168 (2001) 1-46.

[13] Ø. Skreiberg, P. Kilpinen, P. Glarborg, Combust. Flame 136 (2004) 501-518.

[14] J.A. Miller, C.T. Bowman, Prog. Energy Combust. Sci. 15 (1989) 287-338.

[15] J. Bian, J. Vandooren, P.J. Van Tiggelen, Symp. Combust. 23 (1991) 379-386.

[16] M.A. Mueller, R.A. Yetter, F.L. Dryer, Int. J. Chem. Kinet. 32 (2000) 317-339.

[17] P. Dagaut, P. Glarborg, M.U. Alzueta, Prog. Energy Combust. Sci. 34 (2008) 1-46.

[18] R. Mével, S. Javoy, F. Lafosse, N. Chaumeix, G. Dupré, C.-E. Paillard, Proc. Combust. Inst. 32 (2009) 359-366.

[19] S.J. Klippenstein, L.B. Harding, P. Glarborg, J.A. Miller, Combust. Flame 158 (2011) 774-789.

[20] O. Mathieu, E.L. Petersen, Combust. Flame 162 (2015) 554-570.

[21] H. Nakamura, S. Hasegawa, T. Tezuka, Combust. Flame 185 (2017) 16-27.

[22] M. AlAbbad, T. Javed, F. Khaled, J. Badra, A. Farooq, Combust. Flame 178 (2017) 205-216. 
[23] A.R. Amadio, J. de Vries, J.M. Hall, E.L. Petersen, M.W. Crofton, in: 5th Int. Symp. Shock Waves, July 2005, Bangalore, India.

[24] A. Kéromnès, W.K. Metcalfe, K.A. Heufer, N. Donohoe, A.K. Das, C.J. Sung, J. Herzler, C. Naumann, P. Griebel, O. Mathieu, M.C. Krejci, E.L. Petersen, W.J. Pitz, H.J. Curran, Combust. Flame 160 (2013) 995-1011.

[25] O. Mathieu, A. Levacque, E.L. Petersen, Int. J. Hydrogen Energy. 37 (2012) 15393-15405.

[26] G. Dayma, P. Dagaut, Combust. Sci. Technol. 178 (2006) 1999-2024.

[27] R. Sivaramakrishnan, K. Brezinsky, G. Dayma, P. Dagaut, Phys. Chem. Chem. Phys. 9 (2007) $4531-4331$.

[28] Lee Changyoul, Vranckx Stijn, Heufer Karl A, Khomik Sergey, Uygun Yasar, Olivier Herbert, Fernandez Ravi X, Zeitschrift Für Phys. Chemie . 226 (2012) 1.

[29] J.A. Miller, P. Glarborg, Int. J. Chem. Kinet. 31 (1999) 757-765.

[30] Y. Song, H. Hashemi, J.M. Christensen, C. Zou, P. Marshall, P. Glarborg, Fuel 181 (2016) 358365. 


\section{List of Figure Captions}

\section{(Color figures in electronic version only)}

Figure 1: Typical pressure profile (black solid line) and corresponding $\mathrm{OH}^{*}$ signal (solid red line) as well as the determination of the ignition delay time (dashed line).

Figure 4: Effects of equivalence ratio on the ignition delay time of $\mathrm{NH}_{3} /$ air mixtures at 20 and 40 bar. Simulation are based on the mechanism of Mathieu and Petersen [20].

Figure 3: Comparison of experimental dataset from this study and Mathieu and Petersen [20]

Figure 4: : Normalized sensitivity analysis on $\mathrm{OH}$ radical at time of ignition for a $\mathrm{NH}_{3}$ /air mixture at $\phi=2.0, T=1183 \mathrm{~K}$, and $p=20$ bar based on the mechanism of Mathieu and Petersen [20]

Figure 5: Comparison of experimental results with the model predictions from the literature [17,1921] for the fuel-rich mixture at 20 bar.

Figure 6: Reaction pathway analysis for the $\mathrm{NH}_{3} /$ air mixture at time of ignition; $\mathrm{T}=1200 \mathrm{~K}, \mathrm{p}=20$ bar

Figure 7: Sensitivity analysis for NO formation and consumption based on the mechanism of Mathieu and Petersen [20] at 20 bar; left: $\phi=0.5, T=1213 \mathrm{~K}$; middle: $\phi=1.0, T=1263 \mathrm{~K}$; right: $\phi=2.0, T=1183$ K.

Figure 8: Time-dependent NO profile at $1300 \mathrm{~K}$ and 20 bar at different equivalence ratios (left); Simulated products distribution as function of the temperature at 20 bar (right). Model: Mathieu and Petersen [20]. 
List of supplementary material

1. SMM1-revised 